\title{
¿Racismo en la educación inclusiva? Una mirada desde la interculturalidad crítica
}

\author{
¿Racial Discrimination in Inclusive Education? A perspective from critical interculturality
}

Racismo na educação inclusiva? Um Olhar a Partir da Interculturalidade Crítica

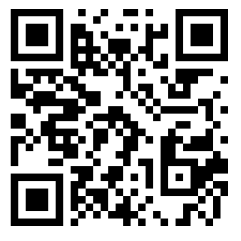

Perrine Delbury

Universidad del Bío Bío

Chillán, Chile

pdelbury@gmail.com

https://orcid.org/0000-0002-4643-2840

Recibido • Received • Recebido: 09 / 02 / 2018

Corregido • Revised $\cdot$ Revisado: 18 / 06 / 2019

Aceptado • Accepted • Aprovado: $13 / 11 / 2019$

\begin{abstract}
Resumen: Existe una sobrerrepresentación de alumnos y alumnas de ascendencia étnica etiquetados como estudiantes con necesidades educativas especiales, un fenómeno observado e investigado a nivel internacional. Este ensayo quiere aportar a la reflexión desde la mirada de la interculturalidad crítica con el objetivo de reconocer y visibilizar la matriz colonial de poder que contextualiza esta problemática. La primera parte establece el marco teórico de los conceptos abordados y la segunda parte es una discusión que expone tres argumentos en torno a la contribución respectiva de las reglas sociales, de las políticas educativasy de la institución escolar en este fenómeno de sobrerrepresentación. Se concluye que, a la base de la propuesta de la educación inclusiva, yace un discurso racista generado por la imposición de una definición monocultural de la normalidad y de discapacidad, y se proponen pistas de reflexión para cambiar la configuración conceptual de la inclusión.
\end{abstract}

Palabras claves: Racismo; educación inclusiva; interculturalidad crítica.

\begin{abstract}
The overrepresentation of ethnic minorities' students as students with special education needs is a well-investigated international phenomenon. This paper is an essay aiming to contribute to the discussion, from the perspective of critical interculturality, to unveil how the phenomenon is embedded into the colonial matrix of power. At first, it presents the theoretical framework of critical interculturality and contextualizes the problem. The second part develops three arguments through a discussion about the respective roles of social rules, public educational policies, and inclusive pedagogy in contributing to this phenomenon. It concludes that, at the foundation of the inclusive education discourse, lays racial discrimination which imposes a monocultural definition of disability and normality to ethnic cultures.
\end{abstract}

Keywords: Racial discrimination; inclusive education; critical interculturality. 
doi: http://doi.org/10.15359/ree.24-1.22

URL: http://www.una.ac.cr/educare

CORREO: educare@una.cr

\begin{abstract}
Resumo: Há uma super-representação de estudantes de origem étnica rotulados como estudantes com necessidades educacionais especiais, fenômeno observado e investigado internacionalmente. Este ensaio quer contribuir a reflexão a partir da perspectiva da interculturalidade crítica, com o objetivo de reconhecer e tornar visível a matriz colonial de poder que contextualiza esse problema. A primeira parte estabelece a perspectiva teórica dos conceitos abordados e a segunda parte apresenta uma discussão que expõe três argumentos sobre a respectiva contribuição das regras sociais, das políticas educacionais e da instituição escolar nesse fenômeno de super-representação. Conclui-se que, na base da proposta da educação inclusiva, reside um discurso racista gerado pela imposição de uma definição monocultural de normalidade e incapacidade, e oferece sugestões de reflexão para mudar a configuração conceitual da inclusão.
\end{abstract}

Palavras-chave: Racismo; educação inclusiva; interculturalidade crítica.

\title{
Introducción
}

La educación inclusiva aspira a hacer efectivo el derecho a una educación de calidad para la diversidad del estudiantado. Se preocupa en particular, y entre otros grupos sociales marginados, "de las personas con discapacidad, ... [y de] las que provienen de etnias o culturas no dominantes, [o] de minorías lingüísticas" (UNESCO, 2008, p. 7). En las escuelas, la idea directriz es "atender la diversidad de necesidades de aprendizaje del alumnado" (UNESCO, 2008, pp. 7-8). Singularmente se ha notado en Norte-América, Oceanía y en Europa una sobrerrepresentación de alumnos y alumnas de origen étnico en la denominada "educación especial" (Cama, 2018; Gutiérrez-Saldivia, 2018; Losen y Ortfield, 2002; Skiba, Poloni-Staudinger, Simmons, Feggins-Azziz; Chung, 2005); en particular por diagnósticos de trastornos emocionales y de comportamiento (Wiley, Brigham, Kauffman y Bogan, 2013), de trastornos del aprendizaje y de déficit mental leve (Zhang y Katsiyannis, 2002). En América Latina, es un fenómeno de desigualdad que recientemente se está investigando en Chile (Gutiérrez-Saldivia, 2018) y que sin duda merece una mayor atención por el aumento de matrícula de alumnos y alumnas de ascendencia étnica con historia de migración o sin esta. Las explicaciones discutidas por la comunidad científica apuntan a las políticas educativas de atención especial que entregan subvenciones individuales por cada diagnóstico y que conducen los establecimientos en la tentación de aumentar la lista del alumnado con necesidades educativas especiales para el buen funcionamiento de la escuela; a la desventaja económica de las poblaciones étnicas (Skiba et al., 2005); a las características biológicas, emocionales, y familiares del estudiantado de grupos minoritarios; a las percepciones del profesorado y las prácticas pedagógicas que no son pertinentes para la totalidad de estudiantes; $y$ al desajuste cultural entre los instrumentos de evaluación, la cultura y la lengua estudiantiles.

Este trabajo quiere agregar a la discusión la perspectiva intercultural crítica de Tubino (2005) y Walsh (2009), la cual establece que todo avance hacia una genuina interculturalidad pasa por reconocer y visibilizar la matriz colonial de poder que construye la diferencia. Se postula que, a la base de la propuesta de la educación inclusiva, yace un discurso racista que impone

2

Perrine Delbury

Los artículos de la Revista Electrónica Educare del Centro de Investigación y Docencia en Educación de la Universidad Nacional, Costa Rica, se comparten bajo términos de la Licencia Creative Commons: Reconocimiento, No Comercial, Sin Obra Derivada 3.0 Costa Rica. Las autorizaciones adicionales a las aquí delimitadas se pueden obtener en el correo: educare@una.cr 
una definición monocultural hegemónica de la discapacidad y de la normalidad al alumnado de origen étnico y termina convirtiendo la diversidad cultural en deficiencia.

Primero se aclararán los conceptos de educación inclusiva, de racismo y de interculturalidad crítica y luego se desarrollan tres argumentos sobre las contribuciones respectivas de la sociedad, el Estado y la escuela en el fenómeno de sobre-etiquetamiento de estudiantes de ascendencia étnica como estudiantes con necesidades educativas especiales. Esta reflexión se dirige en particular a docentes en actividad que indagan sobre los prejuicios, estereotipos, y creencias que sesgan la apreciación de la diversidad de nuestras aulas.

\section{Marco teórico}

A inicios de los noventa, la educación inclusiva es aprobada a nivel internacional como estrategia de equiparación de oportunidades en respuesta al movimiento social de los grupos de personas de la educación especial para una educación pertinente, de calidad y sin discriminación. Desde su institucionalización, la escuela ha tenido funciones concretas: primero, educar a los hijos e hijas de la clase dirigente para la construcción de la nación, luego formar patriotas para respaldar e impulsar a la nación, y luego producir futuros grupos trabajadores, gerentes o gobernantes de la nación, con el fin de contribuir a su prosperidad.

A principio, para la niñez con capacidades o culturas diferentes significó simplemente la exclusión de la escolaridad, luego se crearon instituciones especiales para garantizarle un tipo de educación. Como fruto de la Declaración de los Derechos Humanos de 1949 y de los movimientos sociales que reclaman una educación justa y de calidad, la institución escolar entra progresivamente en una etapa de integración de los grupos históricamente excluidos en la escuela tradicional. En las últimas dos décadas se desarrollaron en paralelo la educación inclusiva, una iniciativa de la educación especial como respuesta a una mejor atención de las necesidades del alumnado con discapacidad, y la educación intercultural, como respuesta a una educación más adecuada a las demandas de los grupos étnicos. Ambas, educación inclusiva e intercultural operan a través de la implementación de programas de atención en la escuela tradicional con impactos directos en el aula de clase.

Una de las líneas de acción de la educación inclusiva es la lucha contra las barreras discriminantes. La discriminación se define en varias dimensiones: sus categorías o tipos, sus mecanismos y sus niveles. Según Rodríguez (2006), "es una conducta, culturalmente fundada, ... de desprecio contra una persona o [un] grupo ... sobre la base de un prejuicio negativo ... relacionado con una desventaja inmerecida, y que tiene por efecto (intencional o no) dañar sus derechos y libertades fundamentales" (Rodríguez, 2006, p. 26). Una situación que denota discriminación será, entonces, cualquier situación en la que, con base en una diferencia entre quien observa y quien es objeto de esa observación, esa diferencia sea utilizada para categorizar como inferior al objeto de observación, sea esto a través de un gesto, una expresión verbal 
doi: http://doi.org/10.15359/ree.24-1.22

URL: http://www.una.ac.cr/educare

CORREO: educare@una.cr

(que puede oscilar desde una supuesta broma hasta una expresión directamente insultante) o una acción física. La discriminación étnica o racismo, que se asocia a alumnado de ascendencia de los pueblos originarios, trata en general de atributos estereotipados y prejuiciados que presupone la superioridad de las normas, valores, y características de tipo europeo. Ha sido también calificado de racismo paternalista por la creencia genuina de la persona que discrimina con sus buenas intenciones hacia el otro.

Lainterculturalidad crítica es una"herramientapedagógica, laqueponeencuestionamiento continuo la racialización, subalternización e inferiorización y sus patrones de poder" (Walsh, 2009, p. 15).

Se entiende como una estrategia, acción y proceso permanentes de relación y negociación entre, en condiciones de respeto, legitimidad, simetría, equidad e igualdad, ... como ... [una] necesidad de cambiar no sólo las relaciones, sino también las estructuras, condiciones y dispositivos de poder que mantienen la desigualdad, inferiorización, racialización y discriminación. (Walsh, 2009, p. 4)

Aún por construir (Walsh, 2009), "[su] foco... no reside solamente en las poblaciones indígenas ..., sino en todos los sectores de la sociedad, con inclusión de los blanco-mestizos occidentalizados" (Rivera, 1999, p. 4). La tarea de la interculturalidad crítica consiste a imaginar cómo conceptuar el reconocimiento cultural y la igualdad social de manera que cada quien apoye a la otra persona en lugar de devaluarla (Tubino, 2005). En el caso de este trabajo, la interculturalidad crítica nos permite hacer un paralelo entre la mirada hegemónica de la discapacidad y la mirada hegemónica de la indigeneidad, aportando una nueva consideración a la problemática de inicio. Para Walsh (2009), el camino del cuestionamiento es la interculturalidad crítica como "enfoque y ... práctica que ... no son funcionales al modelo societal vigente, sino cuestionadores serios de él" (p. 12).

\section{Discusión: El aporte de la interculturalidad crítica a la problemática}

\section{El peso de la historia colonial}

La discapacidad como deficiencia nace en los siglos XVIII y XIX (Skliar, 2000); es un constructo conceptual visto como un problema que responde a una lógica dicotómica cuerpo sano/cuerpo enfermo. En los siglos de desarrollo del capitalismo imperialista, la clase dirigente europea acumula capital y el resto, las clases bajas y los países del Sur, constituye la fuerza laboral que lo produce. Es interesante notar que, en el periodo de colonialismo, los mismos atributos que se usaban para las personas discapacitadas en Europa empezaron a ser usadas para calificar a los pueblos indígenas "a través de discursos normativos tales como, por ejemplo, ausencia de lenguaje, inteligencia primitiva, inmadurez afectiva y cognitiva, comportamientos agresivos, peligrosos, etc." (Skliar, 2000, p. 5). Las 
personas son definidas por la construcción cultural del paradigma dominante sin consideración por su pertenencia o no a la cultura dominante (Lovern, 2008) y son nombradas "discapacitadas" las que no son capaces de trabajar e"indígena" las que no se adhieren al sistema capitalista. Estas definiciones son institucionalizadas a través de los organismos internacionales y de la Convención de los Derechos de las Personas con Discapacidad (que, según el título, no califican como seres humanos), alcanzando, de esta manera, el mayor grado de legitimación posible. Aunque creamos que no hay concepto más confuso e impreciso que la normalidad, esto no impide que recurramos constantemente a una idea subjetiva de ella en nuestra cotidianidad como herramienta de comprensión de las personas y las situaciones. ¿Qué es ser normal? A pesar de no encontrar ningún tipo de consenso al respecto, la respuesta convencional es más sencilla de lo que parece: la normalidad agrupa todas las características que no merecen ser nombradas. Heredadas de la historia, las características normales son las de la clase burguesa europea del siglo XIX, permiten alcanzar más libertad individual y mejores oportunidades de posesión de bienes (claves del éxito social), en concordancia con la lógica capitalista y la mercantilización del trabajo: color blanco, anatomía completa, racionalidad europea/ occidental, género femenino o masculino, y heterosexualidad.

La sociedad mira a las personas desde el paradigma de la normalidad, un paradigma binario heredado del registro medical para la discapacidad y de la conquista de América para la indigeneidad y que se opone al paradigma de la diversidad. Este paradigma parece establecer reglas diferenciales para el progreso social y económico individual, reglas que no son leyes escritas sino valores, discursos, costumbres, creencias que inducen juicios y comportamientos. En lo social, se han generado estereotipos del sujeto discapacitado, incapaz por debilidad o deficiencia físico y mental, y del indígena, incapaz por deferencia mental o flojera, como mecanismos de control de la anormalidad (Pérez-Serrano, 2008). En lo económico-laboral, una persona del grupo dominante tiene más posibilidad de obtener un empleo que una persona de un grupo de capacidad o cultura distinta con la misma certificación, un fenómeno conocido como el "techo limitado de empleo" (Ogbu, 1978). Ser "otro" en la concepción occidental carga connotación negativa de inferioridad, desviación y debilidad (Lovern, 2008). En consecuencia, pensar que la percepción de la sociedad de la realidad social y económica del alumnado con capacidad y cultura distintas no puede tener influencia sobre los actores involucrados en su orientación para su escolarización.

Al contrario, indagarcómo opera el paradigma de la normalidad en las escuelas es un desafió pendiente de la investigación. ¿Qué se les enseña y qué aprenden sobre las realidades sociales y posibilidades económicas de sus grupos dentro de la institución escolar? Si no cuestionamos las raíces históricas e epistemológicas de los términos que usamos cuando nos referimos al alumnado de "ascendencia indígena" o "con discapacidad", ¿cómo saber en qué medida este fenómeno de sobrerrepresentación tiene pertinencia intercultural o si es la consecuencia de un modelo que implícitamente valoriza ciertas capacidades y desvaloriza las otras? ¿Qué impacto tienen los sesgos sociales implícitos sobre nuestra apreciación de la diversidad? Comprender como las reglas sociales influencian nuestras miradas implica cuestionar lo implícito acerca de 
doi: http://doi.org/10.15359/ree.24-1.22

URL: http://www.una.ac.cr/educare

CORREO: educare@una.cr

nuestros juicios y opiniones de la persona con capacidad y cultura distinta, pues, hasta entonces, podremos entender y reparar discriminaciones que en la actualidad no estamos viendo (Devine, Forscher, Austin y Cox, 2012).

Por otro lado, el efecto de las reglas sociales de comportamiento de los alumnos y de las alumnas de ascendencia étnica también tiene su importancia. Cabe comentar acá que en otras epistemes (como la Mapuche o la Nativa Americana), las diferencias de capacidad y de culturas no tienen sistema de valor, ni se diagnostican, ni se clasifican. La capacidad distinta no se problematiza en el sentido de que sus consecuencias en la vida cotidiana ni se constituyen como injusticias que necesitan compensación, como tampoco responden a un modelo médico u social. Todas las personas son reconocidas, participan de labores cotidianas como todas, son susceptibles de aprender como todas, y son portadoras de saberes como todas (Pérez-Serrano, 2008). Se reconoce que cada quien tiene un ritmo y un aprendizaje distinto, no se discute eso, y, por otro lado, se promueve su autonomía. La diferencia es un elemento de la existencia del individuo, pero no el elemento que lo define, y la igualdad de valor aplica a todas las diferencias. En la institución escolar, el alumnado de ascendencia indígena se enfrenta a otro sistema de valores y se inicia en la clasificación social y en las relaciones jerárquicas de la cultura dominante. En el afán de "[calcular], inconscientemente, sus chances contra un orden social adverso" (Da Silva, 1995, p. 202), ¿No estaría llevado a "[desarrollar] estrategias convenientes para lidiar con esa situación de la forma más económica posible, lo que puede incluir una aceptación temporaria de las normas de la escuela?" (Da Silva, 1995, p. 202) ¿No le sería menos problemático recurrir a una especie de resignación cultural, es decir, seguir la corriente del sistema que lo acoge, pero sin "... internalizar disposiciones subordinadas"? (Da Silva, 1995, p. 202) Una anécdota relata que un profesor emérito de origen étnico en Chile se tuvo que conseguir, a petición de la institución escolar, un certificado de salud firmado por distintos profesionales de psicología, fonoaudiología, y neurología, para probar que su hijo no tenía problemas físicos y mentales. Más allá de cuestionar los prejuicios de la escuela hacía el niño de origen étnico, llama la atención que la opinión del propio padre, aún siendo profesor universitario, no tenía validez. El proceso de recolección de firmas de profesionales de la salud significa obviamente tiempo y dinero que no están al alcance de la mayoría de las familias, independientemente de sus orígenes. Valdría indagar qué proporción del alumnado de origen étnico son etiquetados como estudiantes con necesidades educativas especiales por "resignación cultural", pues la adversidad social podría haber llevado al estudiantado de ascendencia étnica y sus familias, a través de una postura defensiva de silencio (Foley, 2004), a crear una "resistencia cultural" (Willis, 1993).

\section{La legitimación de la vulnerabilidad}

Ahora emerge la necesidad de entender cómo el Estado percibe los problemas de la educación, de tomar distancia sobre las políticas educativas, de enmarcarlas en su contexto social, y de investigar desde una postura crítica. En el periodo de construcción de las naciones, 
que buscaron generar una identidad homogénea para patriotas, ambas poblaciones discapacitada e indígena comparten primero una historia de negación y de invisibilización, luego una de discriminación y, finalmente, una de asimilación por parte de la clase dominante. En el último periodo surgen las políticas de compensación, protección, e asistencia para paliar las dificultades que encuentran los grupos sociales marginados en su camino al ideal común. Sin embargo, cualquier dispositivo que compensa o repare, lo que hace primero, es naturalizar un estado de doble vulnerabilidad: ellos o ellas son el problema y no se pueden defender.

La misma sociedad creadora de su vulnerabilidad naturaliza su estatuto de víctimas a través de las políticas públicas. Esta jerarquía de poder entrega al grupo social dominante la oportunidad de definir y de defenderse desde su episteme, dejando a los otros grupos necesitados de protección del Estado sin voz y sin episteme. En el campo educativo, las políticas educativas de inclusión y de interculturalidad operan según esta lógica: definen las características de cultura y de capacidad distintas como vulnerabilidades que necesitan compensaciones para minimizar las diferencias y permitir la adhesión al proyecto hegemónico. Las consecuencias no son menores: primero, los problemas de rendimiento del alumnado de los grupos sociales de discapacidad y de indigeneidad son presentados como exclusivo del alumnado (y no de otros factores) y segundo, el marco institucional escolar en su discurso dice atender la diversidad de alumnos y alumnas, pero en realidad etiqueta sus diferencias, invalida sus conocimientos, y les enseña a estos grupos y a los demás que son vulnerables. ¿Podemos estar seguros de que la ecuación "Otro es igual a Problema", que nos presenta la política educativa de la institución escolar, no influye sobre los actores involucrados al orientarlos para su escolarización? ¿No se malinterpretarán o estigmatizarán las formas de aprendizaje de estudiantes de estos dos grupos sociales?

La educación inclusiva se piensa universal, por responder a todos los tipos de necesidades, y uniforme, por ser igual para todos y todas. Sin embargo, lo declarado por docentes en la bibliografía científica (falta de habilidad para enseñar a estudiantes diferentes; dificultad para enseñar basándose en el principio de igualdad de oportunidades; pedagogía de la diferenciación poco factible en el aula ordinaria) apunta al límite de la pedagogía inclusiva: la racionalidad moderna no es universal, pero sí particular a una relación propia con el mundo. Lo que permite el rendimiento desigual del alumnado es exactamente la suposición de que se ofrece una pedagogía universal e uniforme a un alumnado diverso. No se reconoce la implicación social y cultural de la definición de la discapacidad. El paradigma de la normalidad aflora en la pedagogía inclusiva de varias formas: primero en el hecho que se basa sobre conocimientos "científicos" del desarrollo de la niñez y segundo, a través de los dispositifs de normalización (programas, referencial, evaluación, etc).

Para Bourdieu y Passeron (1970), la pedagogía escolar [tradicional] usa un código de transmisión cultural que solamente los niños y las niñas de la cultura dominante manejan. La idea es que el "proceso de exclusión de las clases subordinadas no se da por ningún acto de imposición brutal y visible, sino por la incapacidad de algunos [grupos sociales] de vencer la 
doi: http://doi.org/10.15359/ree.24-1.22

URL: http://www.una.ac.cr/educare

CORREO: educare@una.cr

carrera 'meritocrática' escolar" (Da Silva, 1995, p. 27). La meritocracia, una discriminación positiva por méritos (de capacidad, de habilidad, de inteligencia, de esfuerzos), es vista por la sociedad, tanto en el mundo laboral como escolar, como fundamentalmente "justa" e "igualitaria". Sin embargo, este modelo de organización escolar solo beneficia a la cultura que define los méritos y que, además, incita a la práctica permanente de la evaluación de estos méritos. Es un sistema que hace parecer sutilmente que las desigualdades no se deben a injusticias culturalmente producidas, sino a la falta de capacidad de la adquisición escolar, un modelo de igualdad de oportunidades basado en el mérito, y por lo tanto, un modelo de igualdad que acepta las desigualdades: todas las personas tienen la oportunidad y las que no lo logran, es que no lo merecían.

La idea de que las [diferentes culturas] están asociadas a tales desigualdades biológicas y que no son, por lo tanto, producto de la historia de las relaciones entre las gentes y de éstas con el resto del universo... [ha] configurado profunda y duraderamente todo un complejo cultural, una matriz de ideas, de imágenes, de valores, de actitudes, de prácticas sociales. .... Ese complejo es lo que conocemos como "racismo". (Quijano, 1993, p. 167)

Poco sentido tiene responder a la diversidad del alumnado con una pedagogía de la normalización. Para las culturas étnicas que no comparten ni el código de transmisión cultural de la cultura dominante ni los principios meritocráticos, es una doble condena que se visibiliza, entre otras formas, a través de esta sobrerrepresentación de alumnos y alumnas de origen étnico en la educación especial.

Lo último nos lleva a cuestionar el proceso evaluativo, basado principalmente en tests psicológicos, usado por los dispositivos de la educación inclusiva para determinar si el alumnado tiene problemas de aprendizaje y emitir un diagnóstico al respeto. Si obviamos las investigaciones que establecen que existen diagnósticos mal emitidos, es decir, que se identifican una discapacidad que no corresponde a la dificultad que tiene o simplemente identifican una discapacidad por una dificultad que no tiene (Lloyd, Kauffman, Landrum y Roe, 1991), podemos en todo caso cuestionar la pertinencia cultural de la evaluación intelectual del alumnado de ascendencia étnica (Herrera, 2017), al igual que la pertinencia de la evaluación lingüística y de la evaluación emocional (Riquelme, Lavoie, Quilaqueo y Quintriqueo, 2017) de las culturas étnicas desde una perspectiva monocultural hegemónica.

La inteligencia, el uso de la lengua y la regulación de emociones son construcciones socioculturales que no tienen significados equivalentes entre culturas. La inteligencia puede ser concebida de varias maneras según la cultura (Sternberg, 2002). Sin embargo, en la educación inclusiva, únicamente la cultura dominante evalúa a sus miembros y miembros de otras culturas con sus propios conceptos de inteligencia. Kincheloe (2004) hace la misma crítica cuando argumenta que las personas de otras culturas no entran en la clasificación psicológica occidental. Lo que aparece como diferencias de propiedad intelectual son diferencias de propiedad cultural (Helms-Lorenz, Van de Vijver y Poortinga, 2003). 
Dos problemas surgen de eso: primero, si imaginamos que cada cultura prepara de forma distinta la regulación de las emociones en la niñez, entonces los perfiles de ideales emocionales no pueden ser los mismos en todas las culturas y lo adecuado en una cultura puede ser visto como inadecuado o emocionalmente incompetente en otra. Segundo, si la construcción de un instrumento de medición cognitiva se hace desde una perspectiva monocultural, entonces el instrumento no puede ser adecuado para otras culturas. La famosa frase "lo que sabía no valía" de los niños y niñas migrantes en España (Franzé, 2002) se puede convertir en "lo que valía para los tests de evaluación intelectual, cultural y emocional, el alumnado de ascendencia étnica no lo sabía".

\section{El impacto de las reglas sociales y de la política de inclusión en las escuelas}

Es importante recordar que la mayoría de los señalamientos de problemas de aprendizaje ocurren en las aulas de clase. Si bien ha sido documentado por la comunidad investigativa que las percepciones del profesorado hacia el alumnado de ascendencia indígena se llenan, a menudo, de prejuicios y de estereotipos, no justifica el sobre-señalamiento de problemas de aprendizaje, pues se sobrepone, en este fenómeno, otra percepción: la que asocia una dificultad de aprendizaje a una patología. Hace diez años no se conocía ni se manejaba el vocabulario de los diagnósticos en las escuelas, mientras ahora se utiliza en las conversaciones de pasillo sin filtro ni precaución, es más, se sustituye a menudo el nombre del alumno o de la alumna por el nombre del diagnóstico.

La obligatoriedad de producir un diagnóstico para poder obtener recursos de apoyo, a través del programa de educación especial, trajo como consecuencia la llegada de un nuevo campo semántico en las escuelas: un alumno ya no es agitado, ahora tiene déficit atencional con hiperactividad; una alumna ya no es confrontativa, tiene un trastorno de oposición desafiante; o ya no es extremadamente tímida, sino que tiene trastorno de personalidad por evitación. En un seminario sobre el aula inclusiva, un profesor de física del Sur de Chile relataba, con una sonrisa, que tenía once "diagnósticos" en su octavo año de educación básica, pero en lugar de incluirle más tiempo en su horario para conocerles mejor, intervenían diversos profesionales en su aula o salían los alumnos y las alumnas a trabajar fuera del aula. Otra profesora compartió que llegaba a recibir cinco profesionales distintos al mismo tiempo en su aula, lo cual generaba una gran confusión en el alumnado y cierta tensión entre profesionales por quién tenía los mejores recursos pedagógicos. En todo caso, las condiciones están dadas para que el profesorado remita los casos de dificultades de aprendizaje a otros grupos profesionales por los programas de atención especial y, por otro lado, no están dadas para que puedan indagar más profundamente sobre el origen de las dificultades del alumnado o simplemente para conocerlo mejor.

En el lenguaje escolar de la cotidianeidad, el alumnado"normal" suele ser el que no nombramos por sus características de género, origen, o capacidad. Si escuchamos a un colega comentarnos que "llegó un alumno nuevo, es nacional; tiene un papá y una mamá, ambos nacionales; habla el idioma 
doi: http://doi.org/10.15359/ree.24-1.22

URL: http://www.una.ac.cr/educare

CORREO: educare@una.cr

nacional, tiene el pelo oscuro y la piel clara; lee, escribe, habla, razona, suma, resta, camina, y corre," nos quedaríamos pensando que mosca lo picó y a que quiere llegar exactamente. Sin embargo, si nos dice "Ilegó un alumno nuevo, es migrante", consideramos que esta característica efectivamente merecía ser señalada, al igual que "no tiene papá", "es disléxica", "es hiperactivo","es negrita","es down". La existencia de estas diferencias implica un sistema de categorías a las cuales se atribuyen un valor normativo. Cuando llamamos un "niño TDAH" o una "niña indígena," transmitimos eficazmente una especie de esencialismo y, aún rechazando la idea de anormalidad, sigue presente de forma implícita cada vez que invocamos su contrario. El uso de estos términos conlleva una carga cultural que no sugiere valor $u$ orgullo, sino que reduce a aquellos niños y a aquellas niñas únicamente a su impedimento. Es un lenguaje que tiende hacia la integración y que configura un mundo tolerante, pero que no considera la persona en su integralidad, mucho menos como sujeto.

Sin embargo, un diagnóstico crea una barrera psicológica por transmitir el mensaje que solo conocimientos médicos permiten comprender al alumno o a la alumna que lo carga, o sea un conocimiento fuera del alcance del profesorado. Instala, además, una relación que se analiza solamente desde el punto de vista de quienes ostentan del privilegio de ser de la cultura hegemónica, al confundir privilegios con derechos. El riesgo que corremos es el de acostumbrarnos a ver un alumno o alumna de ascendencia étnica en los programas de atención especial de la misma forma que nos hemos acostumbrado a la presencia de las personas en mendicidad en la calle, pues no figuran en la agenda de la educación general directrices que trabajen hacía el conocimiento y la comprensión de las culturas étnicas.

\section{A modo de conclusión}

No hay nada parecido a un proceso educativo neutral ... 0 ... funciona como un instrumento utilizado para facilitar la integración de la generación más joven dentro de la lógica del sistema actual... o bien se convierte en la 'práctica de la libertad' [para] la transformación de su propio mundo (Freire, 1994 citado por De Zubiría, 2013, pp. 47-48).

Como hemos visto, desde la construcción social de las definiciones de discapacidad y de normalidad, pasando por las políticas educativas que legitiman esas definiciones y quitan el derecho de autodefinirse o de defenderse, hasta las prácticas pedagógicas del aula inclusiva que los etiqueta, la violencia que vive el alumnado de ascendencia étnica es múltiple. En realidad, la problemática inicial no se puede mirar como una sobrerrepresentación de niños y niñas indígenas con discapacidad, sino que como alumnos y alumnas de ascendencia indígena enfrentándose a una doble dificultad: un constructo hegemónico de la normalidad física y mental y una definición hegemónica de la discapacidad, lo que entrena un racismo de tipo paternalista de parte de la sociedad hegemónica, es decir, que dicta para el alumnado de origen étnico el ideal de un destino común. 
Dentro de la institución escolar, el alumnado étnico se enfrenta a un sistema inclusivo que regula y ordena las relaciones sociales y distribuye el poder, lo que Mignolo (2011) designa como ejemplo por excelencia del alcance de la matriz colonial del poder o de los modos de organización, del ser o de los modos de subjetivación, y del saber o de los modos de conocimiento. Asumir que todas las culturas deberían de encajar dentro de un solo paradigma cultural (el principio hegemónico de la inclusión) nos llevará siempre a las limitaciones de igualdad que conocemos ahora. La estrategia para lograr esa inclusión de un alumnado que históricamente ha sido excluido del sistema escolar tradicional han sido una serie de medidas que etiquetan de una forma $u$ otra este alumnado (programa especial, diagnóstico, etc.) como si fuese la única posibilidad para ellos de sobrevivir dentro de la escuela tradicional. En su afán de promover una igualdad de oportunidad a través de sus programas de atención especializada, lo que realmente hace es proponer una igualdad de oportunidad de adhesión al mundo hegemónico, y no una igualdad de principio como lo establece el primer artículo de la Declaración de los Derechos Humanos.

En consecuencia, la educación inclusiva, a pesar de lo que afirman sus principios, ha instalado una desigualdad dentro de la escuela tradicional que no busca resolverse; al contrario, alimenta la idea de que son diferencias de orden patológico, lo que deja el profesorado con el sentimiento de incompetencia para manejar este alumnado en el aula de clase. Deja a las familias indígenas en la compleja situación de tener que descifrar una interpretación hegemónica que patologiza el aprendizaje y que no existe en su cultura.

Retomando la anécdota mencionada al inicio de este ensayo, el profesor emérito, desde su etiqueta de indígena, debió usar los instrumentos occidentales para mostrar que su hijo no pertenece a otra categoría mental impuesta proporcionada por la cultura dominante que no existe en su propia cultura. El hecho de que solo disponen para pensar de instrumentos elaborados y compartidos con los dominantes y de carecer de instrumentos intelectuales para pensar o actuar de otra forma es una violencia simbólica (Bourdieu, 2008).

Si el racismo conceptual está unánimemente condenado y si la ciencia ya desestimó la existencia de razas biológicas, no significa que el racismo empírico este desapareciendo, sino que simplemente evoluciona con su tiempo. El cuestionamiento desde la interculturalidad crítica de este fenómeno de desproporcionalidad nos permite reflexionar sobre la igualdad que realmente queremos. Sentirse igual a Otro ser supone un sentimiento de cercanía hacía ese Otro ser. En otras palabras, cuanto menos semejantes nos sentimos, menos deseamos la igualdad de aquello que no conocemos. En el mundo escolar, las medidas que marcan y formalizan las diferencias del alumnado, como por ejemplo el uso del vocabulario médico asociado a los diagnósticos, participan activamente del alejamiento mutuo entre profesorado, alumnado tradicional, alumnado con necesidades especiales y alumnado de origen étnico. Tanto los programas de inclusión como los programas de educación intercultural siguen en una óptica de asimilación del alumnado de ascendencia étnica a la cultura hegemónica y no en 
doi: http://doi.org/10.15359/ree.24-1.22

URL: http://www.una.ac.cr/educare

CORREO: educare@una.cr

la construcción de un apego a los lazos sociales que nos llevan a desear la igualdad de todos los seres humanos. La sobrerrepresentación de alumnado étnico en la educación especial es solamente un síntoma de un mal mayor que es el aumento progresivo de las desigualdades sociales y territoriales, al cual las políticas educativas de inclusión e intercultural contribuyen alimentando el racismo paternalista y la fragmentación de la sociedad.

Afortunadamente, la constatación de este riesgo nos conduce a una posible reconceptualización de la inclusión a nivel de las aulas de clase, a través de prácticas sociales y pedagógicas relativamente simples. Crear lazos, producir apego, edificar la fraternidad son esenciales para aceptarse mutualmente como diferentes en características e iguales en derechos. Las pedagogías que promueven la construcción de lazos sociales en las escuelas, como las de Célestin Freinet, Francisco Ferrer, y Paulo Freire, existen desde hace más de cincuenta años; sin embargo, no han logrado instalarse y propagarse en los sistemas educacionales. Pero es posible hacerlo, como lo demuestran las multitudes comunidades escolares de pedagogías humanistas. Se trata de devolverles la voz a los actores de las escuelas, tanto al profesorado como al alumnado de todos los orígenes, mediante la realización de actividades o proyectos que se construyen en conjunto, donde la toma de decisiones sea compartida y el relato sea común.

No hay lugar más indicado para luchar por la desigualdad que un aula de clase donde se encuentran día tras día los ciudadanos y las ciudadanas en formación. Esta lucha depende de nuestra capacidad de vivir juntos y juntas en el lugar donde nos encontramos y si no lo logramos en un lugar delimitado como el aula, ¿cómo esperar lograrlo en la sociedad? La interculturalidad crítica contribuye a nuestra formación como agentes sociales críticos y competentes, y nos empodera en el momento de recibir un alumno o una alumna de origen étnico en nuestra aula porque nos orienta hacía la comprensión de sus emociones en lugar de la categorización de sus dificultades, y nos abre a otras epistemes en lugar de quedarnos en la racionalidad hegemónica y monocultural. Lo importante es reconocer que el modelo de inclusión propuesto desde la política educativa no nos permite construir un relato común con nuestro alumnado, pero como docentes sí tenemos la opción de elegir otro modelo de inclusión, uno de fraternidad y de igualdad.

\section{Declaración de Financiamiento}

Este trabajo fue financiado por CONICYT PSFCHA/DOCTORADO BECANACIONAL/2018-21180630.

\section{Referencias}

Bourdieu, P. (2008). Capital cultural, escuela y espacio social. Buenos Aires: Siglo XXI Editores.

Bourdieu, P. y Passeron, J.-C. (1970). La reproduction éléments pour une théorie du système d'enseignement. Paris: Minuit. 
Cama, A. (2018). La sobrerrepresentación de escolares de nacionalidad extranjera en el grupo de alumnado con necesidades educativas especiales. Revista Internacional de Estudios Migratorios, 8(1), 1-22. doi: https://doi.org/10.25115/riem.v8i1.2075

Da Silva, T. T. (1995). Escuela, conocimiento y currículum. Ensayos críticos. Buenos Aires: Miño y Dávila.

De Zubiría, J. (2013). ¿Cómo diseñar un currículo por competencias? Fundamentos, lineamientos y estrategias. Bogotá: Magisterio.

Devine, P. G. Forscher, P. S., Austin, A. J. y Cox, W. T. L. (2012). Long-term reduction in implicit race bias: A prejudice habit-breaking intervention. Journal of Experimental Social Psychology, 48(6), 1267-1278. doi: https://doi.org/10.1016/j.jesp.2012.06.003

Foley, D.E.(2004). El indígena silencioso como una producción cultural.Cuadernos de Antropología Social, 19, 11-28. Recuperado de https://www.redalyc.org/pdf/1809/180913911002.pdf

Franzé, A. (2002). Lo que sabía no valía. Escuela, diversidad e inmigración. Madrid: Consejo Económico y Social de la Comunidad de Madrid. Recuperado de https://www.academia. edu/10623714/Lo que sab\%C3\%ADa no val\%C3\%ADa escuela diversidad e inmigraci\%C3\%B3n

Gutiérrez-Saldivia, X. (2018). Desproporcionalidad de estudiantes de grupos minoritarios en la educación especial. Revista Espacios, 39(43), 33-46. Recuperado de https://www. revistaespacios.com/a18v39n43/18394333.html

Helms-Lorenz, M., Van de Vijver, F. J. y Poortinga, Y. H. (2003). Cross-cultural differences in cognitive performance and Spearman's hypothesis: g or c? Intelligence, 31(1), 9-29. doi: https://doi.org/10.1016/S0160-2896(02)00111-3

Herrera, V. (Octubre, 2017). Decreto 170, Diagnóstico y pertinencia cultural:Un desafío pendiente. Trabajo presentado en el IV Congreso internacional sobre educación e interculturalidad. Temuco, Chile: RIEDI.

Kincheloe, J. L. (2004). Into the great wide open: Introducing critical thinking. En D. Weil and J. Kincheloe (Eds.), Critical thinking and learning: An encyclopedia for parents and teachers (pp. 1-52). Westport: Greenwood Press.

Lloyd, J. W., Kauffman, J. M., Landrum, T. J. y Roe, D. L. (1991). Why do teachers refer pupils for special education? An analysis of referral records. Exceptionality, 2(3), 115-126. doi: https:// doi.org/10.1080/09362839109524774 
doi: http://doi.org/10.15359/ree.24-1.22

URL: http://www.una.ac.cr/educare

CORREO: educare@una.cr

Losen, D. J. y Orfield, G. (2002). Introduction. Racial inequality in special education. En D. J. Losen y G. Orfield (Ed.), Racial inequity in special education (pp.15-37). Cambridge: Harvard Education Press.

Lovern, L. (2008). Native American Worldview and the discourse on disability. Essays in Philosophy, 9(1), 1-9. Recuperado de https://commons.pacificu.edu/cgi/viewcontent. cgi?article $=1300 \&$ context $=$ eip

Mignolo, W. (2011). The darker side of western modernity. Global futures, decolonial options. North Carolina: Duke University Press. doi: https://doi.org/10.1215/9780822394501

Ogbu, J. (1978). Minority education and caste: The American System in cross-cultural perspective. New York: Academic Press.

Pérez-Serrano, G. (2008). Una aproximación a la identidad en los discapacitados mapuche de la comunidad Kallfulikan, en la Comuna de La Florida (Tesis de Grado). Universidad Academia e Humanismo Cristiano, Santiago. Recuperado de http://bibliotecadigital.academia.cl/ bitstream/handle/123456789/627/tant83.pdf? sequence=1\&isAllowed =y

Quijano, A. (1993). "Raza", "etnia" y "nación" en Mariátegui: Cuestiones abiertas. En R. Forgues (Ed.), José Carlos Mariátegui y Europa. La otra cara del descubrimiento (pp. 166-187). Lima: Amauta.

Riquelme, E., Lavoie, G., Quilaqueo, D. y Quintriqueo, S. (2017). Emotion and exclusion: Key ideas from Vygotsky to review our role in a school with a cultural diversity setting. Revista Brasileira de Educaçao Especial 23(2), 169-184. doi: http://dx.doi.org/10.1590/S1413$\underline{65382317000200002}$

Rivera, S. (1999). Anotaciones fragmentarias en torno a la interculturalidad. En M.A. García Blanco (Comp.), Encuentro México-Bolivia sobre cultura, identidad y globalización (pp. 104114). La Paz: Uma Phajsi.

Rodríguez, J. (2006). Un marco teórico para la discriminación (Colección Estudios 2). México: Consejo Nacional para Prevenir la Discriminación. Recuperado de https://www.conapred. org.mx/documentos cedoc/E0002(1).pdf

Skiba, R. J., Poloni-Staudinger, L., Simmons, A., B., Feggins-Azziz, R., y Chung, C.-G. (2005). Unproven links: Can poverty explain ethnic disproportionality in special education? The Journal of Special Education 39(3), 130-144. doi: https://doi.org/10.1177/00224669050390 $\underline{030101}$ 
Skliar, C. (2000). Discursos y prácticas sobre la deficiencia y la normalidad. Las exclusiones del lenguaje, del cuerpo y de la mente. En P. Gentili (Coord.), Códigos para la ciudadanía. La formación ética como práctica de la libertad (pp. 1-13). Buenos Aires: Santillana. Recuperado de https://www.canales.org.ar/archivos/lectura recomendada/Skliar-Santilla-1.pdf

Sternberg, R. (2002). Cultural explorations of human intelligence around the world. En W. J. Lonner, D. L. Dinnel, S. A., Hayes y D. N. Sattler (Eds.), Online readings in psychology and culture (Unit 5, Chapter I). Bellingham, Washington: Center for Cross-Cultural Research, Western Washington University.

Tubino, F. (Enero, 2005). La interculturalidad crítica como proyecto ético-político. Trabajo presentado en el Encuentro continental de educadores agustinos. Lima, Perú. Recuperado de http://oala.villanova.edu/congresos/educación/lima-ponen-02.html

UNESCO. (Noviembre, 2008). La educación inclusiva: El camino hacia el futuro (Conferencia Internacional de Educación, cuadragésima octava reunión). Ginebra: Autor. Recuperado de $\quad$ http://www.ibe.unesco.org/fileadmin/user upload/Policy Dialogue/48th ICE/ CONFINTED 48 Inf 2 Spanish.pdf

Walsh, C. (2009). Interculturalidad crítica y educación intercultural. Trabajo presentado en el seminario Interculturalidad y Educación Intercultural del Instituto Internacional de Integración del Convenio Andrés Bello en La Paz, Bolivia. Recuperado de http://www.uchile. cl/documentos/interculturalidad-critica-y-educacion-intercultural 1105970 2405.pdf

Wiley, A. L., Brigham, F. J., Kauffman, J. M. y Bogan, J. E. (2013). Disproportionate poverty, conservatism, and the disproportionate identification of minority students with emotional and behavioral disorders. Education and Treatment of Children, 36(4), 29-50. doi: https:// doi.org/10.1353/etc.2013.0033

Willis, P. (1993). Producción cultural no es lo mismo que reproducción cultural, que a su vez no es lo mismo que reproducción social, que tampoco es lo mismo que reproducción. En $\mathrm{H}$. M. Velazco, F. J. García y Á. Díaz (Eds.), Lecturas de antropología para educadores. El ámbito de la antropología de la educación y de la etnografía escolar (pp. 431-461). Madrid: Trotta.

Zhang, D. y Katsiyannis, A. (2002). Minority representation in special education: A persistent challenge. Remedial and Special Education, 23(3), 180-187. doi: https://doi.org/10.1177/07 $\underline{419325020230030601}$ 